\title{
Adenotonsillar Hypertrophy in Pre-School Children with Sickle Cell Disease and Diagnostic Accuracy of the Sleep Disturbance Scale for Children
}

\author{
Carlos Rodolfo Tavares de Góis ${ }^{1}$ Jeferson Sampaio D’Ávila ${ }^{1}$ Rosana Cipolotti ${ }^{1}$ Amanda da Silva Lira ${ }^{2}$ \\ Ana Letícia Leite Silva ${ }^{1}$ \\ ${ }^{1}$ Department of Medicine, Universidade Federal de Sergipe (UFS), \\ Aracaju, SE, Brazil \\ 2 Department of Statistics and Actuarial Sciences, Universidade \\ Federal de Sergipe (UFS), São Cristóvão, SE, Brazil

\begin{abstract}
Address for correspondence Carlos Rodolfo Tavares de Góis, PhD, Rua Dr. Celso Oliva, 250, Torre B, Apto. 802, Bairro 13 de Julho, Aracaju, SE, Brazil CEP: 49020-090 (e-mail: carlosrtgois@yahoo.com.br).
\end{abstract}

Int Arch Otorhinolaryngol 2018;22:55-59.

\begin{abstract}
Keywords

- hypertrophy

- pharyngeal tonsil

- palatine tonsil

- sickle cell disease

Introduction Adenotonsillar hypertrophy is more common in children with sickle cell disease, and can lead to sleep-disordered breathing.

Objectives To determine the frequency of adenotonsillar hypertrophy in pre-school children with sickle cell disease and assess the diagnostic accuracy of the sleepdisordered breathing subscale in the Sleep Disturbance Scale for Children.

Method Observational study with a group of 48 children with sickle cell disease and a control group of 35 children without the disease. The children underwent oropharingoscopy and video nasal endoscopy. The parents and/or guardians answered the questions of the subscale.

Results Adenotonsillar hypertrophy was observed in $25 \%$ of the children in the study group, and in $20 \%$ of the children in the control group, with no statistical difference between the groups. The subscale score ranged from 3 to 11 in both groups. There was a statistical significance in the study group. The average was 4.79 (standard deviation $[S D] \pm 2.50)$, with 4.19 (SD \pm 1.72$)$ among the children without adenotonsillar hypertrophy, and 6.5 (SD \pm 3.40 ) among the children with adenotonsillar hypertrophy. There was also a statistical significance in the control group. The average was 5.23 (SD \pm 2.81 ), with 4.44 (SD \pm 2.2 ) among the children without adenotonsillar hypertrophy, and 7.87 ( $S D \pm 2.89$ ) among the children with adenotonsillar hypertrophy.

Conclusion Adenotonsillar hypertrophy was not associated with sickle cell disease in pre-school children. The subscale of sleep-disordered breathing in the Sleep Disturbance Scale for Children was a useful tool for the diagnostic suspicion of adenotonsillar hypertrophy in children in this age group.
\end{abstract}

\section{Introduction}

Sickle cell disease (SCD) is a systemic nosological disease characterized by progressive damage in several organs; it is considered one of the most serious monogenic diseases. It received this denomination because of the sickle-shaped erythrocytes of the patients. Sickle cell anemia (SCA) is the most common form of the disease, and specifically refers to received

November 12, 2016

accepted

March 18, 2017

published online

May 2, 2017
DOI https://doi.org/

10.1055/s-0037-1602702. ISSN 1809-9777.
Copyright $(2018$ by Thieme Revinter

Publicações Ltda, Rio de Janeiro, Brazil
License terms

(ㄷ) (i) $\ominus$ (\$) 
the homozygosity of the $\beta$ S-globin allele, which leads to the production of a particular type of hemoglobin, that is, hemoglobin $\mathrm{S}(\mathrm{HbS})$. There is also sickle cell (SC) hemoglobinopathy, which results from the relationship of the $\beta$ S-globin allele and the $\beta$ C-globin allele with $\beta$-thalassemia resulting from the combination of the $\beta$ S-globin allele with the $\beta$-thalassemia allele, causing the $\mathrm{HbS} / \beta$-thalassemia. ${ }^{1}$

The clinical manifestation of SCD basically occurs due to two processes: a) vas occlusion, with ischemia and reperfusion injuries; and b) hemolytic anemia. ${ }^{2}$ Bacterial infections are the leading cause of morbidity and mortality, and they result from hyposplenism, disorders in the activation of the complement system, micronutrient deficiency, and tissue ischemia. $^{3}$

Adenotonsillar hypertrophy (ATH) is the term commonly used to describe the abnormal growth of the pharyngeal tonsil (adenoid vegetations) and palatine tonsils. Although this growth can arise from a hyperplastic process of the lymphoid cells of these tissues, this differentiation is clinically irrelevant. ${ }^{4}$

The causes of ATH are not yet fully known; however, recurring chronic or acute inflammation seem to be involved, since children subject to these processes usually exhibit an abnormal growth of cervical and pharyngeal lymphoid tissues. $^{5}$

Adenotonsillar hypertrophy seems to be more frequent and to have a tendency to be extended in children with SCD, which may result in recurrent pharyngitis. There are three hypotheses suggested for the association between ATH and SCD: compensation for autosplenectomy; consequence of recurrent infections of the upper airways due to failed opsonization of pathogenic bacteria; and the function of pharyngeal and palatine tonsils as hematopoietic centers due to hemolysis. Adenotonsillar hypertrophy can lead to sleep-disordered breathing (SDB), which varies from snoring to obstructive sleep apnea syndrome, with resulting hypoxemia, hypercapnia, and acidosis, raising the risk of $\mathrm{HbS}$ polymerization and, consequently, vaso-occlusive phenomena and other complications, such as transient ischemic attacks and cerebrovascular accident. ${ }^{6,7}$

The Sleep Disturbance Scale for Children (SDSC) is a questionnaire validated for the Portuguese language that has been increasingly used in studies on SDB in children and adolescents. ${ }^{8}$

The goals of the present study were to assess the association between SCD and ATH, and the diagnostic accuracy of the SDCS for ATH in pre-school children with SCD.

\section{Method}

The study group was composed of children aged between 2 and 6 years, who attended the specialized outpatient clinic of the regional university public service. They were recruited by the researcher during routine appointments. The control group consisted of healthy children of the same age, who attended two-day care centers. One of these centers belonged to the municipal network, and the other to the private network, and both were located in the suburbs of the capital of the state. In order to recruit the children of the control group, we sent invitation letters to their parents and/ or legal guardians from the two day care centers.

The criteria for inclusion in the study group were: a) having a diagnosis of SCD confirmed by the quantitative analysis of the hemoglobin, performed through hemoglobin electrophoresis or high-performance liquid chromatography; and b) being clinically stable. The criteria for inclusion in the control group were: a) no diagnosis of SCD; and b) no acute infectious process. The exclusion criteria for the two groups were: a) exhibiting craniofacial malformations; b) debilitating diseases; c) recent craniofacial trauma; d) adenoidectomy surgery and/or previous tonsillectomy; and e) undergoing systemic therapy with corticosteroids during the study.

The parents and/or guardians of the children who were willing to participate in the study signed an informed consent form. Subsequently, they answered three questions related to SDB in the Portuguese version of the SDSC. The subscale was composed of three items: a) the child does not breathe well during sleep; b) the child stops breathing for a few moments during sleep; and c) the child snores. The score of each item varied from 1 (never) to 5 (always), considering the frequency during the previous 6 weeks. ${ }^{8}$ Subsequently, the children underwent oropharingoscopy with frontal lighting and tongue depressor, and video nasal endoscopy using a 3.2-mm flexible endoscope (Machida Endoscope Co., Tokyo, Japan) coupled to a LED light source (Lumen), and a digital microcamera (Pro-HD II - Pillertech Equip. Ltda, Curitiba, Brazil) to record the images for analysis.

The palatine tonsils were classified according to Brodsky's criteria, ${ }^{9}$ namely: grade $0=$ palatine tonsils located inside the tonsillar fossae; grade $1=$ tonsils located beyond the tonsillar fossae, occupying less than $25 \%$ of the airspace in the oropharynx; grade 2 = tonsils occupying more than $25 \%$ and less than $50 \%$ of the oropharyngeal space; grade $3=$ tonsils occupying more than $50 \%$ and less than $75 \%$ of the oropharyngeal space; grade $4=$ tonsils occupying more than $75 \%$ of the oropharyngeal space. Palatine tonsils with grades 3 or 4 were considered obstructive. The pharyngeal tonsil (adenoid) was considered obstructive when there was choanal occlusion of at least $70 \%{ }^{10}$ The children with adenoid and/or obstructive palatine tonsils were diagnosed with ATH. ${ }^{11}$

The data were analyzed using the Statistical Package for the Social Sciences (SPSS) software, version 16 (SPSS Inc., Chicago Il, US). After determining the normality of the sample distribution, the data were compared using the chi-squared test for categorical variables, and the MannWhitney test for continuous variables. Values of $p<0.05$ were considered significant.

The project was approved by the Research Ethics Committee of the institution, under CAAE Protocol No. 23646413.6.0000.5546.

\section{Results}

A total of 48 children were eligible for the study group, 22 boys and 26 girls. Of these, 40 were diagnosed with SCA, and 8 had SC hemoglobinopathy. The control group 
Table 1 Age-related distribution of patients with adenotonsillar hypertrophy in the study group

\begin{tabular}{|l|l|l|}
\hline \multirow{2}{*}{ Age (years) } & Patients \\
\cline { 2 - 3 } & No. & $\mathbf{( \% )}$ \\
\hline 2 & 1 & 8.3 \\
\hline 3 & 1 & 8.3 \\
\hline 4 & 3 & 25 \\
\hline 5 & 4 & 33.3 \\
\hline 6 & 3 & 25 \\
\hline TOTAL & 12 & 100 \\
\hline
\end{tabular}

was composed of 35 children ( 27 boys and 8 girls). There was no statistical difference between the groups $(p=0.369)$. The average age of the study group was 4.04 years (standard deviation [SD]: \pm 1.458 ), and the average age of the control group was 4.25 years (SD: \pm 1.120 ), with no statistically significant difference $(p=0.5764)$.

We observed that ATH occurred in 12 children of the study group (25\%), 7 boys and 5 girls. In the control group, 7 children (20\%) exhibited ATH (6 boys and 1 girl). There was no significant difference between the frequencies in the two groups $(p=0.246)$. As it can be seen in - Table 1, there was no association between ATH and age in the study group ( $p=0.831$ ); however, that association occurred in the control group $(p=0.043)$, in which we observed a higher frequency of ATH in children under 5 years of age ( - Table 2 ).

The score obtained in the three items of the SDB subscale in the SDSC ranged from 3 to 11 in both groups. In the study group, the average was 4.79 ( $\mathrm{SD} \pm 2.50$ ), with 4.19 $(\mathrm{SD} \pm 1.72)$ among the children without ATH, and 6.5 (SD x2009; \pm 3.40 ) among the children with ATH. There was a statistical significance in the study group $(p=0.0025)$. In the control group, the average was 5.23 ( $\mathrm{SD} \pm 2.81$ ), with $4.44(\mathrm{SD} \pm 2.2)$ among the children without $\mathrm{ATH}$, and $7.87(\mathrm{SD} \pm 2.89)$ among the children with ATH. There also was a statistical significance in this group $(p=0.0026)$.

Table 2 Age-related distribution of patients with adenotonsillar hypertrophy in the control group

\begin{tabular}{|l|l|l|}
\hline \multirow{2}{*}{ Age (years) } & Patients \\
\cline { 2 - 3 } & No. & $\mathbf{( \% )}$ \\
\hline 2 & 0 & 0 \\
\hline 3 & 1 & 14.3 \\
\hline 4 & 1 & 14.3 \\
\hline 5 & 4 & 57.1 \\
\hline 6 & 1 & 14.3 \\
\hline TOTAL & 7 & 100 \\
\hline
\end{tabular}

\section{Discussion}

The results demonstrated that the groups were comparable, since both of them exhibited statistically similar sex and age distribution. Even though there was a significantly greater proportion of boys in the control group, this fact would probably not interfere in the frequency of ATH because, as already demonstrated in several studies, this disease has shown similar prevalence between sexes. ${ }^{5,10}$ We also observed equal SCD distribution between the sexes, which is in line with the findings of national and international medical studies. $^{12,13}$

The age group most affected by ATH ranges from 2 to 6 years and, after this age, there is an involution process of the lymphoid tissue in the pharynx..$^{5,10,14,15}$ For this reason, we decided to study children in this age group. One study found a prevalence peak between 3 and 5 years. ${ }^{5}$ In the present study, we only found an association between age and ATH in the control group, and it was more frequent among 5-year-old children.

Regarding the frequency of $\mathrm{ATH}$, the two groups also showed a similarity. In the literature consulted, the prevalence of ATH ranged from 11 to $37.6 \%,{ }^{16,17}$ which was in line with the findings of our study. Other studies have estimated the prevalence of SDB, whose main cause in children is $\mathrm{ATH},{ }^{4,14,18}$ characterized by the occurrence of snoring as an isolated signal (primary snoring), or associated with an increased resistance of the upper airways, with obstructive hypoventilation until the complete collapse, leading to obstructive sleep apnea syndrome. ${ }^{18,19}$ While primary snoring affects 9 to 29\% of children, SDB with hypoventilation and apnea occurs in 1 to $4 \%$ of children. ${ }^{18,20}$ Among the other causes of SDB, obesity, craniofacial malformations, neurological diseases, and gastroesophageal reflux disease stand out. $^{19,21,22}$

One limitation of the present study was that we did not assess body mass index, craniofacial measures, and the Mallampati classification, which is based on the proportion between the tongue and the pharynx, and is routinely used in sleep medicine. However, as the focus of the study was the association between ATH and SCD, and considering the difficulty of a detailed assessment in children in this age group, we only observed the degree of nasal obstruction caused by the pharyngeal and palatine tonsils. It is possible that the use of topical and systemic corticosteroids may transiently affect the degree of nasal obstruction and, even, the tonsillar dimensions, ${ }^{23,24}$ although this hypothesis has been refuted by some authors. ${ }^{25}$

Following the methodology of other studies, ${ }^{11,12}$ we chose to consider only the use of systemic corticosteroids during the otorhinolaryngologic examination as an exclusion criterion, because there was great difficulty in obtaining reliable information about the recent use of medications from the parents and/or guardians of the children. In addition, there is scarce literature on the duration of the effects caused by various corticosteroids on the pharyngeal and palatine tonsils.

Although some authors have reported a higher prevalence of ATH among children with $\mathrm{SCD},{ }^{6,11,26}$ the analysis of the 
results of the present study did not detect a significant difference between the children with SCD and those of the control group. It is worth mentioning that the children with SCD were recruited at the time of their pediatric appointments. They were accompanied by the parents in the health care service, and there was no refusal to participate in the study.

On the other hand, the children of the control group were recruited by means of invitation letters, which explained what ATH was, the symptoms, the effects, and the method that we would use for the diagnosis. In this way, we may have created a selection bias, since the parents of the children with SDB symptoms may have had greater interest in the assessment, allowing the physical examination and the video nasal endoscopy. However, given the wide acceptance on the part of the parents, possibly due to the difficult access to specialized examinations, as well as the fact that we found the frequency of ATH to be within the expected range according to the literature, ${ }^{16,17}$ we believe that this was not an important limitation of our study.

In fact, we observed a clear divergence with respect to the ATH frequency in children with SCD, when compared with the findings of previous studies. A study showed palatine tonsil hypertrophy in $55 \%$ of 53 patients with SCD, whose ages ranged from 1.9 to 16.5 years, although the measurement scale for the tonsils was not the same as the scale used in our study. ${ }^{26}$

A national study found that ATH had a frequency of 55.3\% in patients with SCD aged between 2 and 19 years. Although the authors used Brodsky's classification for the assessment of the palatine tonsils in a way similar to ours, they considered that the pharyngeal tonsils were hypertrophic when they occluded more than $50 \%$ of the choanae, which certainly contributed to increase the frequency of ATH in comparison to our sample. ${ }^{11}$ Even though other authors have also worked using this percentage to consider adenoidal obstruction, ${ }^{27}$ we used a minimal choanal occlusion of $70 \%$ to consider the pharyngeal tonsil obstructive.

The data from the literature indicate an absence of association between the dimensions of the palatine and pharyngeal tonsils and the severity of the $\mathrm{SDB}^{10,14}$; however, with the daily practice of otorhinolaryngology physicians can perceive that children with pharyngeal tonsil exhibiting an occlusion degree lower than $70 \%$ exhibit signs and symptoms compatible with SDB. On the other hand, regarding the palatine tonsils, we agreed that the occupation of more than $50 \%$ of the oropharynx (Brodsky's grades 3 and 4 ) should be considered obstructive, because it is unlikely to find palatine tonsils with those dimensions without the presence of adenoid vegetations closing at least half of the choanae. This fact was confirmed in our sample, as well as in a previously published study. ${ }^{11}$ In this case, it is believed that the joint obstructive action of the palatine and pharyngeal tonsils would lead to nasal obstruction symptoms.

Studies have demonstrated that children with SCD and adenoid vegetations, even with obstruction below $70 \%$, exhibit a higher apnea-hypopnea index than children without SCD. ${ }^{6,11,18}$ However, it is possible that this occurs due to other reasons relating to $S C D$, because obstructive sleep apnea syndrome has a multifactorial etiology. ${ }^{19,21,22}$

One study used magnetic resonance imaging to compare the dimensions of the lymphatic organs of the head and neck in patients with and without SCD. The authors observed that all of these organs, including the pharyngeal and palatine tonsils, had significantly increase in the patients with SCD. ${ }^{6}$ On the other hand, the present study aimed to detect an association between SCD and obstructive ATH, and not simply the relative increase in lymphoid tissue in patients with SCD.

The SDSC, which assesses a variety of sleep-related behavior patterns in children, has six subscales for diagnosing parasomnias, difficulty in initiating and maintaining sleep, SDB, excessive daytime sleepiness, hyperhidrosis, and nonrestorative sleep. The six subscales have a total of 26 items, with scores ranging from 1 (never) to 5 (always). ${ }^{8,28}$ In the present work, we initially tried to work using the SDSC in its entirety; however, there was a great difficulty on the part of the parents and/or guardians of the children to properly understand and answer the questions, probably due to their low level of formal education.

In addition, the sample would hardly be sufficient to generate reliable results in the assessment of some sleep disorders. As the priority of the study was to assess ATH in children with SCD and in controls, we decided to use only the items related to SDB (13 to 15 ), and the total score ranged from 3 to 15 points.

As expected, when we analyzed the SDSC score, we did not find a higher score in children with ATH in the two groups; however, we only observed a statistical significance in the group of children with SCD. It is possible that the number of children in the control group has hindered the observation of the statistical evidence of this association. There are no studies comparing the score of SDB in the SDSC in pre-school children with or without ATH, and only two studies have used the SDSC in pre-school children. In the first one, which assessed a sample of 904 children aged from 3 to 6 years, the average score was $4.4(\mathrm{SD} \pm 1.6) .{ }^{29}$ The second study involved 601 children in the same age group, and the score ranged from 3 to 14, with an average of $4.79(S D \pm 1.91) .{ }^{30}$ These results were very close to those of our study. In the study by Bruni, Ottaviano and Guidetti, with patients aged from 6 to 16 years, the average score was $3.77(\mathrm{SD} \pm 1.45),{ }^{28}$ which probably reflected the lower prevalence of ATH in this age group.

\section{Conclusion}

In the present study, ATH was not associated with SCD in preschool children. The subscale of SDB in the SDSC proved to be a useful tool for the diagnostic suspicion of ATH in pre-school children.

\section{References}

1 Okoli K, Irani F, Horvath W. Pathophysiologic considerations for the interactions between obstructive sleep apnea and sickle hemoglobinopathies. Med Hypotheses 2009;72(05):578-580 
2 Franceschi L. Pathophisiology of sickle cell disease and new drugs for the treatment. Medit J Hemat Infect Dis. 2009. Open Journal System

3 Serjeant GR, Serjeant BE. Sickle cell disease. Oxford UK: Oxford University Press; 2001

4 Potsic WP. Assessment and treatment of adenotonsillar hypertrophy in children. Am J Otolaryngol 1992;13(05):259-264

5 Yaseen ET, Khammas AH, Anbaky FA. Adenoid enlargement assessment by plain X- ray and nasoendoscopy. Iraqui J Comm Med. 2012;1:88-91

6 Strauss T, Sin S, Marcus CL, et al. Upper airway lymphoid tissue size in children with sickle cell disease. Chest 2012;142(01): 94-100

7 Warrier R, Chauhan A, Athale U. Tonsillectomy and adenoidectomy for obstructive sleep apnea in sickle cell anemia. Indian J Pediatr 2010;77(06):669-672

8 Ferreira VR, Carvalho LBC, Ruotolo F, de Morais JF, Prado LBF, Prado GF. Sleep disturbance scale for children: translation, cultural adaptation, and validation. Sleep Med 2009;10(04): 457-463

9 Brodsky L. Modern assessment of tonsils and adenoids. Pediatr Clin North Am 1989;36(06):1551-1569

10 Valera FCP, Avelino MAG, Pettermann MB, et al. OSAS in children: correlation between endoscopic and polysomnographic findings. Otolaryngol Head Neck Surg 2005;132(02):268-272

11 Salles C, Ramos RTT, Daltro C, Nascimento VM, Matos MA. Association between adenotonsillar hypertrophy, tonsillitis and painful crises in sickle cell disease. J Pediatr (Rio J) 2009;85(03): 249-253

12 Felix AA, Souza HM, Ribeiro SBF. Aspectos epidemiológicos e sociais da anemia falciforme. Rev Bras Hematol Hemoter 2010;32(3): 203-208

13 Platt OS, Brambilla DJ, Rosse WF, et al. Mortality in sickle cell disease. Life expectancy and risk factors for early death. N Engl J Med 1994;330(23):1639-1644

14 Tagaya M, Nakata S, Yasuma F, et al. Relationship between adenoid size and severity of obstructive sleep apnea in preschool children. Int J Pediatr Otorhinolaryngol 2012;76(12):1827-1830

15 Pac A, Karadag A, Kurtaran H, Aktas D. Comparison of cardiac function and valvular damage in children with and without adenotonsillar hypertrophy. Int J Pediatr Otorhinolaryngol 2005;69(04):527-532

16 Kara CO, Ergin H, Koçak G, Kiliç I, Yurdakul M. Prevalence of tonsillar hypertrophy and associated oropharyngeal symptoms in primary school children in Denizli, Turkey. Int J Pediatr Otorhinolaryngol 2002;66(02):175-179

17 Abreu RR, Rocha RL, Lamounier JA, Guerra AF. Etiology, clinical manifestations and concurrent findings in mouth-breathing children. J Pediatr (Rio J) 2008;84(06):529-535

18 Salles C, Ramos RTT, Matos MA. Apneia obstrutiva do sono em portadores de anemia falciforme. Rev Bras Hematol Hemoter 2010;32(01):70-75

19 Aubertin G. Le syndrome d'apnées obstructives du sommeil chez l'enfant. Rev Pneumol Clin 2013;69(04):229-236

20 Piteo AM, Lushington K, Roberts RM, et al. Prevalence of snoring and associated factors in infancy. Sleep Med 2011;12(08): 787-792

21 Miranda GN. Trastornos respiratorios del sueño en la edad pediátrica. Rev Med Clin Las Condes 2013;24:403-411

22 Salles C, Bispo M, Trindade-Ramos RT. Association between morphometric variables and nocturnal desaturation in sicklecell anemia. J Pediatr (Rio J) 2014;90(04):420-425

23 Cho D-Y, Sinha SR, Gardner JM, et al. Effect of intratonsillar injection of steroids on the palatine tonsils of rabbits. Laryngoscope 2014;124(12):2811-2817

24 Demain JG, Goetz DW. Pediatric adenoidal hypertrophy and nasal airway obstruction: reduction with aqueous nasal beclomethasone. Pediatrics 1995;95(03):355-364

25 Al-Ghamdi SA, Manoukian JJ, Morielli A, Oudjhane K, Ducharme FM, Brouillette RT. Do systemic corticosteroids effectively treat obstructive sleep apnea secondary to adenotonsillar hypertrophy? Laryngoscope 1997;107(10):1382-1387

26 Samuels MP, Stebbens VA, Davies SC, Picton-Jones E, Southall DP. Sleep related upper airway obstruction and hypoxaemia in sickle cell disease. Arch Dis Child 1992;67(07):925-929

27 D'Ávila JS, Naves AB, Chagas L, et al. Adenoidectomia: novos princípios. Estudo interdisciplinar. Rev Bras Otorrinolaringol 1999;65:511-516

28 Bruni O, Ottaviano S, Guidetti V, et al. The Sleep Disturbance Scale for Children (SDSC). Construction and validation of an instrument to evaluate sleep disturbances in childhood and adolescence. J Sleep Res 1996;5(04):251-261

29 Simola P, Niskakangas M, Liukkonen K, et al. Sleep problems and daytime tiredness in Finnish preschool-aged children-a community survey. Child Care Health Dev 2010;36(06):805-811

30 Romeo DM, Bruni O, Brogna C, et al. Application of the sleep disturbance scale for children (SDSC) in preschool age. Eur J Paediatr Neurol 2013;17(04):374-382 